Ann. Génét. Sél. anim., I969, 1 (1), I5-I8.

\title{
ACROTERIASIS CONGENITA DANS LA RACE PIE NOIRE DES PLAINES EN POLOGNE
}

\author{
H. GERINGER \\ Chaire de Zootechnie, \\ École supérieure d'A griculture, Wroclaw, Pologne
}

SOMMAIRE

On a retrouvé en Pologne dans la race Pie noire des Plaines, le défaut héréditaire d'amputation congénitale (Acroteriasis congenita) déjà signalé dans de nombreux autres rameaux de la branche européenne de la race Frisonne pie noire.

Sur le territoire rattaché au Centre d'Insémination de Karczow, près d'Opole, 3 veaux anormaux sont nés en I966 et 67 dans la descendance du taureau frison pie noir Joukje's Gerard Wouter, $5037 \mathrm{~K}$, importé des Pays-Bas (No FRS 57674).

Les désordres anatomiques qui les caractérisent sont donnés dans le tableau I ainsi que les durées de gestation, le sexe des veaux étant malheureusement inconnu. Les pedigrees sont présentés dans la figure $\mathrm{I}$.

Le veau $n^{0} 2$ est très sommairement décrit, mais les défauts des membres des veaux $\mathrm{I}$ et 3 sont du type ectromélien (amputation), en outre les malformations de la tête du veau $n^{\circ}$ I rappellent les symptômes de l'otocéphalie.

La durée de gestation moyenne de ces 3 anormaux est de 266 jours contre 280 jours pour la durée moyenne dans la race pie noire. Pour les veaux I et 2 les pedigrees montrent qu'il peut s'agir d'un déterminisme héréditaire monofactoriel récessif.

Bien qu'incomplets, les renseignements dont on dispose permettent de faire le rapprochement avec une anomalie héréditaire bien connue dans le rameau européen de la race frisonne pie noire : acroteriasis congenita encore appelée amputation congénitale ou ectromélie et otocéphalie. L,es données anatomiques peuvent en effet, présenter une certaine variation dans les malformations qui accompagnent l'ectromélie, comme nous l'enseignent RIECK et B̈̈HR (I967). En outre, 


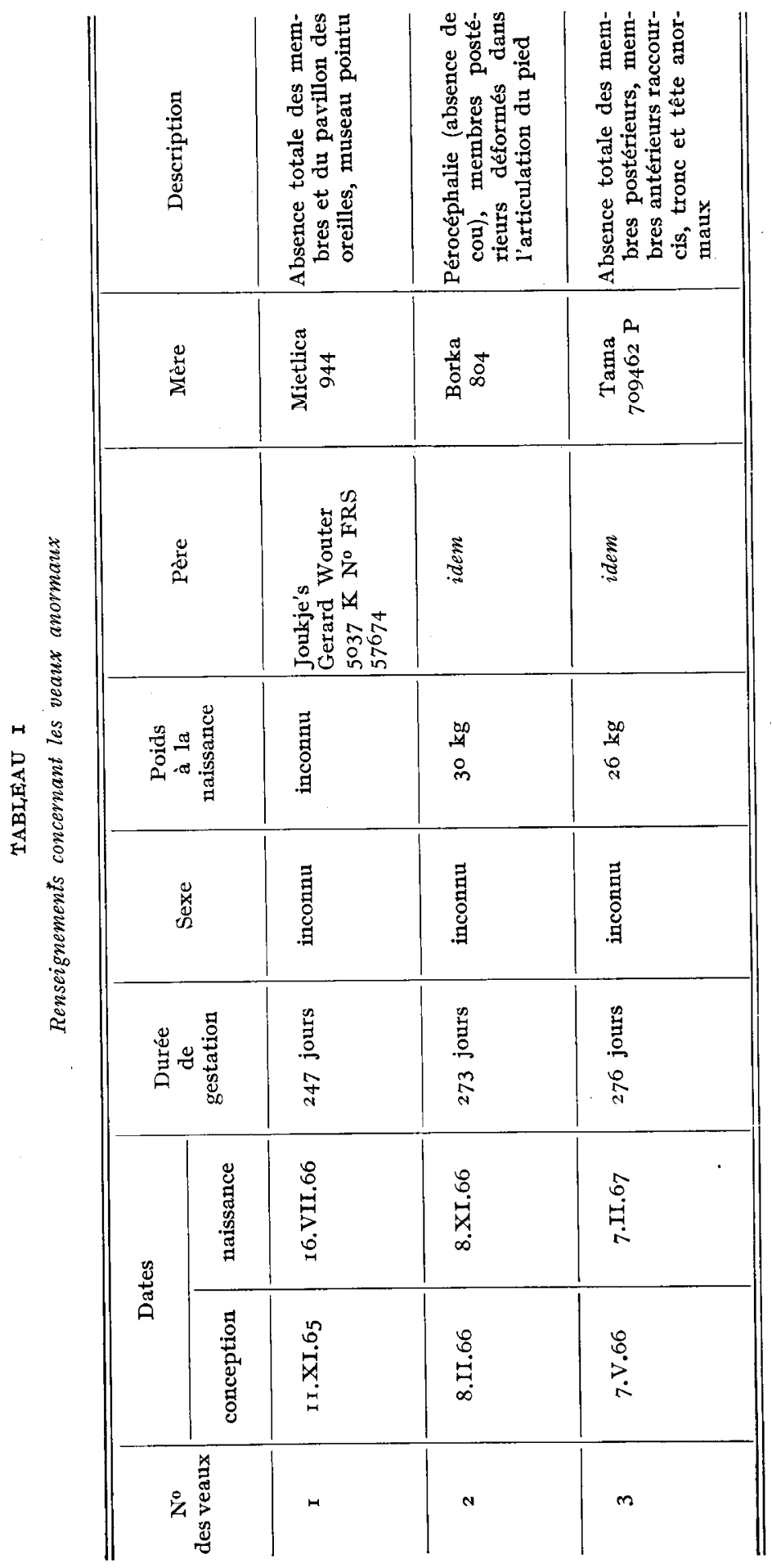


on relève après LAUVERGNE et CUQ (I963) un raccourcissement notable de la durée de gestation. Enfin, le pedigree du père des 3 anormaux remonte à des. ancêtres qui figurent déjà parmi les ascendants de certains taureaux hétérozygotes étudiés par les deux derniers auteurs : les animaux qui portent les nos FRS 30587 (Anna's Adema) et 28773 .

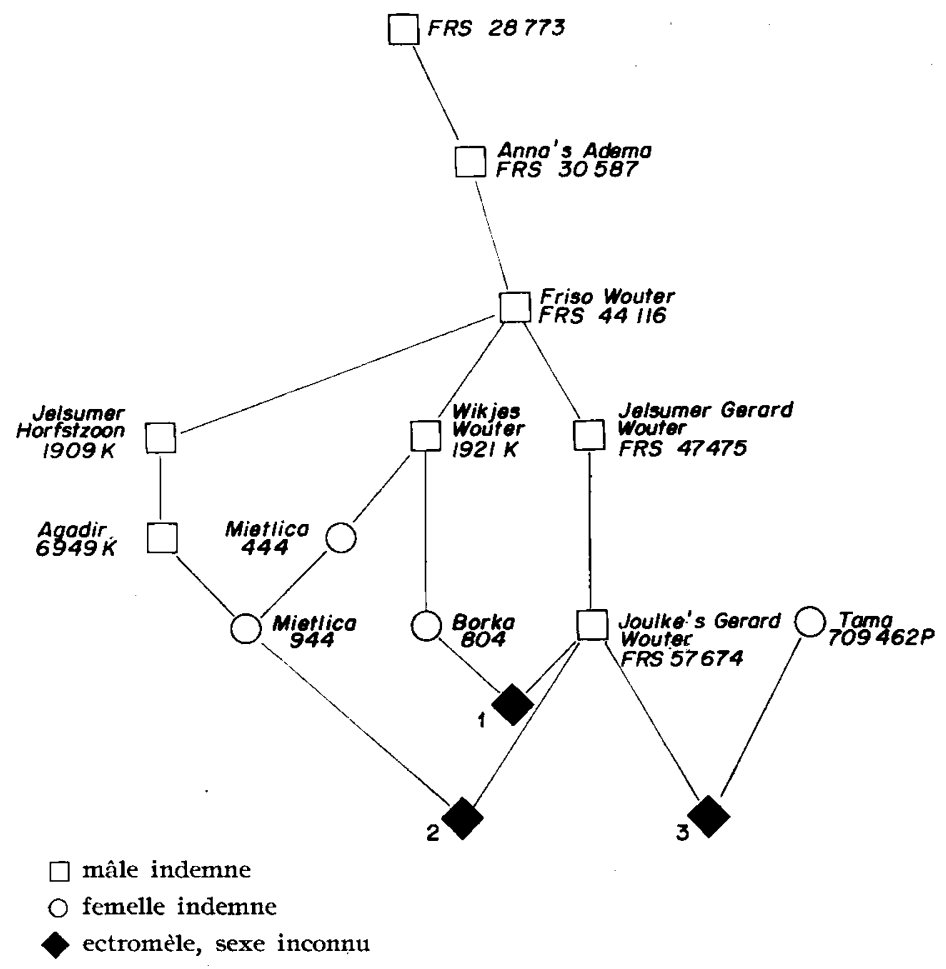

FIG. I. - Pedigree des veaux anormaux

Friso Wouter, ancêtre commun par le père et la mère de deux des trois anormaux et arrière-grandpère du troisième, est demi-frère de FRS 42697 et oncle de FRS 33562 . Ces deux taureaux sont, d'après I,AUVERGNe et CuQ ( 1963 ), hétérozygotes pour le facteur d'amputation congénitale.

Cette anomalie a été signalée pour la première fois en Suède par WRIEDT et Mohr (I928) qui ont forgé le terme d'Acroteriasis congenita. Par la suite on 1'a identifiée aux Pays-Bas, en Israël, Indonésie, France, Égypte et Allemagne. LAUVERGNE (I968) l'a répertoriée sous le no 83 dans son catalogue des anomalies héréditaires en proposant le nom d'ectromélie et otocéphalie, en accord avec son système terminologique.

Cette monstruosité est sans doute le défaut héréditaire le plus répandu dans le rameau européen de la race frisonne pie noire. Dans cette race où, par le passé, une consanguinité assez intense a été pratiquée, réduisant considérablement l'effectif génétique de certaines générations, on ne doit pas s'étonner de trouver de tels gènes, conservés par les hasards de la dérive génétique. Si, actuellement, 
la dispersion de l'ectromélie, vu le nombre de pays atteints, peut paraître impressionnante, la fréquence génique est en définitive très faible. Il ne semble pas, en outre, qu'il existe, dans les zones qui pratiquent l'insémination artificielle, un danger de voir augmenter cette fréquence par l'introduction des taureaux frisons des Pays-Bas souvent utilisés comme améliorateurs car, dans la province de Frise, on pratique, dans le cadre du testage, la détection des hétérozygotes (1). Bien sûr, le criblage n'est pas parfait à cause de la faible fréquence du gène chez les femelles et du fait que beaucoup de jeunes taureaux sont vendus sans avoir été testés, mais cela ne peut être vraiment inquiétant à l'échelon de la population.

Ręu pour publication en octobre $\mathrm{I} 968$.

\author{
SUMMARY \\ CONGENITAL ACROTERIASIS IN THE BLACK PIED BREED (FRIESIAN) \\ OF THE POLISH PLAINS
}

In Poland during the year 1966, three abnormal calves were sired by a bull of the Friesian (Black pied) breed which had been imported from the Netherlands. Although the descriptions are brief, the anatomical defects resemble those of the hereditary abnormality congenital acroteriasis, also called congenital amputation or ectromely and otocephaly. Further characteristics such as the reduced length of gestation, the recessive nature of the defect, and the relationship of the bull to animals reported to be carriers in other countries, leads to believe that the defect is really caused by the gene whose presence has been reported practically everywhere that the European branch of the Friesian (Black pied) breed is produced.

\title{
RÉFÉRENCES BIBLIOGRAPHIQUES
}

I.AUVERGne J. J., 1968. Catalogue des anomalies héréditaires des bovins, Bull. tech. Dép. Génét. anim. (Inst. nation. Rech. agron., Fr.), no $\mathrm{n}, 9 \mathrm{x}$.

I,auvergne J. J., CuQ P., 1963. Ectromélie et otocéphalie en race française frisonne pie noire. $A n n$. Zootech., 12, 181-192.

RIECK G. W., B̈̈HR H., 1967. Akroteriasis congenita beim deutschen schwarzbunten Rind. Dt. tierärztl. Wschr., 74, 356-364.

WRIEdT C., MOHR O. L., 1928. Amputated, a recessive lethal in cattle. J. Genet., 20, 187-215.

(1) Cf. les listes des taureaux d'insémination soumis au testage chaque année: K. I. Stieren in Friesland, I963-64 ou $1964-65$ par exemple. 